\title{
Sodium Dodecylsulfate-Polyacrylamide Gel Electrophoresis
}

National Cancer Institute

\section{Source}

National Cancer Institute. Sodium Dodecylsulfate-Polyacrylamide Gel Electrophoresis. NCl Thesaurus. Code C18150.

Sodium dodecyl sulfate (SDS) polyacrylamide gel electrophoresis is a procedure for estimating molecular weights of polypeptides, and uses SDS, a detergent that dissociates and unfolds oligomeric proteins into its subunits. The SDS binds to the polypeptides to form complexes with fairly constant charge to mass ratios. The electrophoretic migration rate through a gel is therefore determined only by the size of the complexes. 